\title{
On the Problem of Management of Physical Education of Younger Schoolchildren Using Modular Substitutions of Structural Bases of The Educational Subject
}

\author{
Anatoliy Matveev ${ }^{1 *}$, Anna Skotnikova ${ }^{1}$, Vasiliy Belyaev ${ }^{1}$, and Natalya Nikolaeva ${ }^{1}$ \\ ${ }^{1}$ Moscow City University, Moscow, Russia
}

\begin{abstract}
The work aims to improve the quality of education of primary school students in physical education by introducing a scientifically-based exemplary program into the practice of educational organizations developed following the basic provisions of the modular approach and the principles of managing the educational process. Analysis and synthesis of literature data on modern trends in the development of the education system, the experience of educational organizations, and the development of the fundamentals of a physical education subject are used as the main research methods. The result of the work is the substantiation of conceptual approaches and methodological provisions on the formation of the structure and content of an exemplary Modular educational program in physical education, criteria, recommendations for the meaningful filling of its training modules, the technology of their substitution in the educational process.
\end{abstract}

\section{Introduction}

The transition of a society to the market path of development in the late twentieth century was marked by a change in the social doctrine of the development of the Russian Federation, the basis of which began to be a liberal ideology. As a result of the adoption of liberal values in Russian education, there is a transition from a fundamental socialist goal that focuses on "the upbringing of a comprehensively and harmoniously developed personality, the builder of society" to the target setting of protestant individualism, which focuses education on "the development of a personality capable of independent and responsible thinking and to think" $[1,2]$. The implementation of this target setting in the practice of Russian educational institutions has revealed the unwillingness of the Russian education to actively develop on the principles of a liberal education when instead of preparing a socially significant person (a person for society) it was necessary to prepare an individually significant person (a person for themself) $[2,3]$.

To resolve the contradiction between these two different goals in education, Russian pedagogy took advantage of the liberal theory of a personality-oriented approach and began

*Corresponding author: apmatveev0609@mail.ru 
to actively "transform" its positions into constructive components of the traditional Russian model of education. The selective approbation of such "transformation" showed the possibility to have a targeted effect on the formation of students' personality, to inculcate the interest in the realities of the world around us, including physical education activities $[4,5]$.

Based on the above mentioned, it is possible to conclude that one of the relevant directions in the development of Russian education, including education on physical culture, is the search for scientific-founded approaches to the development of substantive content of Russian education, to orient it to achieve the requirements of the Federal State Education Standards (FSES). The urgency of scientific search in this direction is enhanced by the rapid adoption of a new educational standard, the draft of which is currently under general discussion.

\section{Research objective}

To propose conceptual constructs for the preparation of the Modular Educational Program on Physical Education for Primary School Students, based on the modular approach developed in Russian pedagogy.

\section{Methods}

The study was carried out based on the Institute of Natural Sciences and Sports Technologies of the Moscow City Pedagogical University, as part of the execution of an order of research by the Moscow Department of Education. The main research method was the analysis and synthesis of literature data, normative documents, the practice of educational institutions in Moscow.

\section{Results and discussion}

Having traveled a fairly long way from 1993 to 2010, Russian pedagogy formulated the modern goal of the Russian education system, which in a generalized form focuses on the formation of highly moral, creative, competent and successful citizens of Russia capable of active development and self-determination in personal, social and professional activities [6, 7]. Private educational theories have worked out relatively independent target settings for invariant educational disciplines, which included physical education to achieve this goal, taking into account the accumulated value orientations and pedagogical approaches. As a result of orientation towards the formation of an individually significant student's personality (a person for themself), the goal of this discipline is "preparing a comprehensively and harmoniously developed personality that can creatively use the values of physical culture to strengthen and maintain its own health, optimize work, organize individual leisure and leisure time" $[8,9]$.

It was proposed in the system of established GSSO requirements adopted in 2004 to achieve the goal by introducing curricula in educational organizations based on the previously developed concept of physical education for schoolchildren [8]. The basic provisions of the theory of leading activity in ontogenesis, activity, and competence approaches were used as the methodological basis of this concept, which allowed replacing the educational subject of physical training, for the teaching subject of motor activity. According to the structural organization of this activity, the modern subject of physical culture is presented by three main blocks: "Knowledge of physical culture" (component); "Methods of independent organization of classes" (operational component) and "Physical improvement" (motivationally transformative component) [6]. The substantial content of 
these three interconnected blocks orients the educational process to the development of students' knowledge, skills, and abilities to independently strengthen their health, the active use of physical culture and sports, and the organization of a healthy lifestyle. The conditions for the formation and development of individual personal self-determination of students are created as a consequence of the conversion of the subject of physical culture to the holistic personality of students (to oneself). By acquiring personal meaning, education in physical culture becomes the basis for the formation of the interest of schoolchildren in physical culture and sports.

The above judgments make it possible to conclude that by focusing on transforming the physical nature of students, physical training remains relevant to the educational system in the various dynamic economic, industrial, and social conditions. Mobile transforming in its goals, objectives, means, and methods under emerging needs and requirements, it remains in demand on the part of the Russian education system, characterized by its objective significance, both for students themselves and society as a whole" [10].

The development of information and communication technologies, the expansion of the spectrum of computer support for the learning process, the increase in the number of computer games of different target and content, the intensive spread of esports among students. These and other phenomena caused a relatively dramatic decline in student motor activity. As a consequence of the strengthening of this negative trend, the Ministry of Education of the Russian Federation by its order of August 30, 2010 No. 889 introduces an additional mandatory third hour of physical education into the weekly educational regime of educational organizations. According to the methodological recommendations attached to this order, the introduction of the third hour of physical education is caused by the objective need to strengthen the role of physical culture in the upbringing of the younger generation, strengthen its health, and increase the amount of physical activity [11].

The introduction of the third lesson of physical culture in secondary general educational organizations caused the emergence of several problems in the organization of a holistic educational process, including in educational organizations of the city of Moscow. As the results of the study showed, the most urgent for the Moscow education system was the problem of the content of the third lesson of physical education, the definition of its pedagogical expediency, the relationship with the content of the corresponding lines of textbooks.

The lack of proper scientific research of this problem and its immediate effective resolution, not the development of methodical support, led to the development of the third lesson as a relatively independent form of the educational process, the content of which has become determined by the level of professional readiness of the teacher and the sufficiency of logistical support educational process. The observed "relative independence" of physical education teachers in the organization and content of the third lesson led to a wide range of their targeted orientation and subject content. The opportunity to actively use the content of sports in the education of schoolchildren on physical culture, predetermined the beginning of the development of working programs replacing the educational subject motor activity for physical training [11].

Thus, from the above analysis of the history of the development of schoolchildren's education in physical education, it becomes obvious that the theory and methodology of pedagogy actualize the problem of finding new approaches to the formation of the foundations of the content of the relevant educational discipline. The solution to this problem depends on the development of conceptual provisions for the preparation of training programs on physical culture, determination of their target orientation, content, and structural organization.

We tested the main provisions of the Modular educational program on physical education focusing on the results of a retrospective analysis and the data on the modern development 
of the subject matter of the discipline of physical education. A distinctive feature of this program is the use of a modular approach developed in Russian pedagogy $[12,13]$. The following judgments are the main provisions underlying its development:

1. The modular program focuses on achieving the basic goal of schoolchildren's education in physical education, which is related to the fulfillment of the basic requirements of the Federal State Educational Standard (2010).

2. The modular program consists of two learning blocks: invariant and variative. The invariant block includes the content of one of the author's programs on physical culture. The variative block consists of programs of modular disciplines for sports, the choice of which is carried out by teachers.

3. The modular program focuses on students' learning topics related to the development of physical qualities. These topics in both blocks of the program are divided into three large groups:

- knowledge of means and methods of physical training;

- skills in the planning of independent forms of physical education using physical training facilities.

4. The variative block of the modular program includes training modules, the content of which is a certain sport, focusing on the targeted development of a particular physical quality.

5. The content of the modular program is developed at a rate of 104 hours in the annual budget of the study load. Of these, 68 hours are devoted to the development of educational material of the invariant block and 36 hours to the variative block. In the weekly training cycle, when planning the program material, it is supposed to devote two lessons to solving the problems of basic physical education (invariant block) and one lesson to the problems of physical preparation (variative block).

6. Training modules of the modular program are worked out in such a way that complex modules can be formed from them. The basis of such integrated modules can be the teaching topics of programs such as "Methods of organization of independent propulsion activities" and "Physical improvement" in terms of solving the problems of physical training.

8. Each module of the Module Program has certain completeness and is oriented towards obtaining a specific planned result. Development indicators of the corresponding physical quality, the development of which is oriented to a particular sport, act as such a result.

\section{Conclusion}

Suggestions have been made for the creation of a modular educational program in physical education for elementary school students in the context of considering the historical and modern development of the substantive foundations of the Russian education system. This program is developed on modern scientific approaches proposed by Russian pedagogy and orienting the process of education of schoolchildren on the formation of the ability of active self-determination in the field of physical culture and healthy lifestyles.

\section{References}

1. N.A. Alekseev, Personality-oriented training. Issues of theory and practice: Monograph (Publishing House of the Tyumen State University, Tyumen, 1996)

2. Yu.M. Bulygina, F.V. Monakhov, E.A. Cheremisova, Psychology, Sociology and Pedagogy 9, 67 (2014)

3. S.V. Kulikova, Izv. Volgogr. State Ped un-y. Ser.: Pedagogical sciences 9(94), 39-43 (2014) 
4. T.A. Papikyan, AV. Obmoina, The state of the education system in modern Russia and its relevance. Education: past, present and future: materials of the III Intern. scientific conference, Krasnodar, Russia (2017)

5. Order of the Ministry of Education of the Russian Federation No. 1089 "On the approval of the federal component of state educational standards of primary general, basic general and secondary (complete) general education" (March 5, 2004) Available at: http://www.edu.ru/documents/view/61154/

6. A.P. Matveev. The concept of the structure and content of education in physical education at school. Physical Culture: education, training, training 6, 2-5 (2005)

7. Decree of the Government of the Russian Federation No. 751 "On the National Doctrine of Education in the Russian Federation" (October 4, 2000) Available at: https://rg.ru/2000/10/11/doktrina-dok.html

8. A.P. Matveev, Theoretical and methodological foundations of the formation of the subject "physical education" in a comprehensive school: diss ... doc. ped Sciences (NSU n.a. P.F. Lesgaft, St. Petersburg, 1997)

9. A.P. Matveev, On the problem of the methodological support of innovative educational programs in physical education. "Education and training of young children": Collection of scientific articles (Lomonosov Moscow State University, Moscow, 2018)

10. A.P. Matveev, Bulletin of sports science 1, $71-75$ (2019)

11. Order of the Ministry of Education and Science of the Russian Federation No. 889 "On Amending the Federal Basic Curriculum and Sample Curricula for Educational Institutions of the Russian Federation Implementing General Education Programs" (August 30, 2010) Available at: http://www.edu.ru/documents/view/50069/

12. Yu.V. Golovanova, Young scientist 12(59), 437-442 (2013)

13. O.N. Oleinikova, A.A. Muravyev, Yu., N. Konovalova, Modular technologies: design and development of educational programs (Infra-M, Moscow, 2010)

14. C.A. Egan, C. Webster, G. Stewart, Evaluation and Program Planning 72, 106-117 (2019)

15. J.V. Nielsen, Evaluation and Program Planning 76, (2019) 